\title{
Impact of supine versus upright exercise on muscle deoxygenation heterogeneity during ramp incremental cycling is site specific
}

\author{
Richie P. Goulding ${ }^{1,2,3}$ (]) Dai Okushima ${ }^{4} \cdot$ Yoshiyuki Fukuoka $^{5} \cdot$ Simon Marwood $^{6} \cdot$ Narihiko Kondo $^{7}$. \\ David C. Poole $^{8} \cdot$ Thomas J. Barstow $^{8} \cdot$ Shunsaku Koga ${ }^{2}$
}

Received: 30 October 2020 / Accepted: 17 January 2021 / Published online: 11 February 2021

(c) The Author(s) 2021

\begin{abstract}
Purpose We tested the hypothesis that incremental ramp cycling exercise performed in the supine position $(S)$ would be associated with an increased reliance on muscle deoxygenation (deoxy[heme]) in the deep and superficial vastus lateralis (VLd and VLs, respectively) and the superficial rectus femoris (RFs) when compared to the upright position $(U)$.

Methods 11 healthy men completed ramp incremental exercise tests in $S$ and $U$. Pulmonary $\dot{V} \mathrm{O}_{2}$ was measured breath-bybreath; deoxy[heme] was determined via time-resolved near-infrared spectroscopy in the VLd, VLs and RFs.

Results Supine exercise increased the overall change in deoxy[heme] from baseline to maximal exercise in the VLs ( $S$ : $38 \pm 23$ vs. $U: 26 \pm 15 \mu \mathrm{M}, P<0.001)$ and RFs ( $S: 36 \pm 21$ vs. $U: 25 \pm 15 \mu \mathrm{M}, P<0.001)$, but not in the VLd (S: $32 \pm 23$ vs. $U: 29 \pm 26 \mu \mathrm{M}, P>0.05)$.

Conclusions The present study supports that the impaired balance between $\mathrm{O}_{2}$ delivery and $\mathrm{O}_{2}$ utilization observed during supine exercise is a regional phenomenon within superficial muscles. Thus, deep muscle defended its $\mathrm{O}_{2}$ delivery/utilization balance against the supine-induced reductions in perfusion pressure. The differential responses of these muscle regions may be explained by a regional heterogeneity of vascular and metabolic control properties, perhaps related to fiber type composition.
\end{abstract}

Keywords Near-infrared spectroscopy $\cdot$ Oxygen delivery $\cdot$ Oxygen utilization $\cdot$ Exercise tolerance $\cdot$ Muscle activation

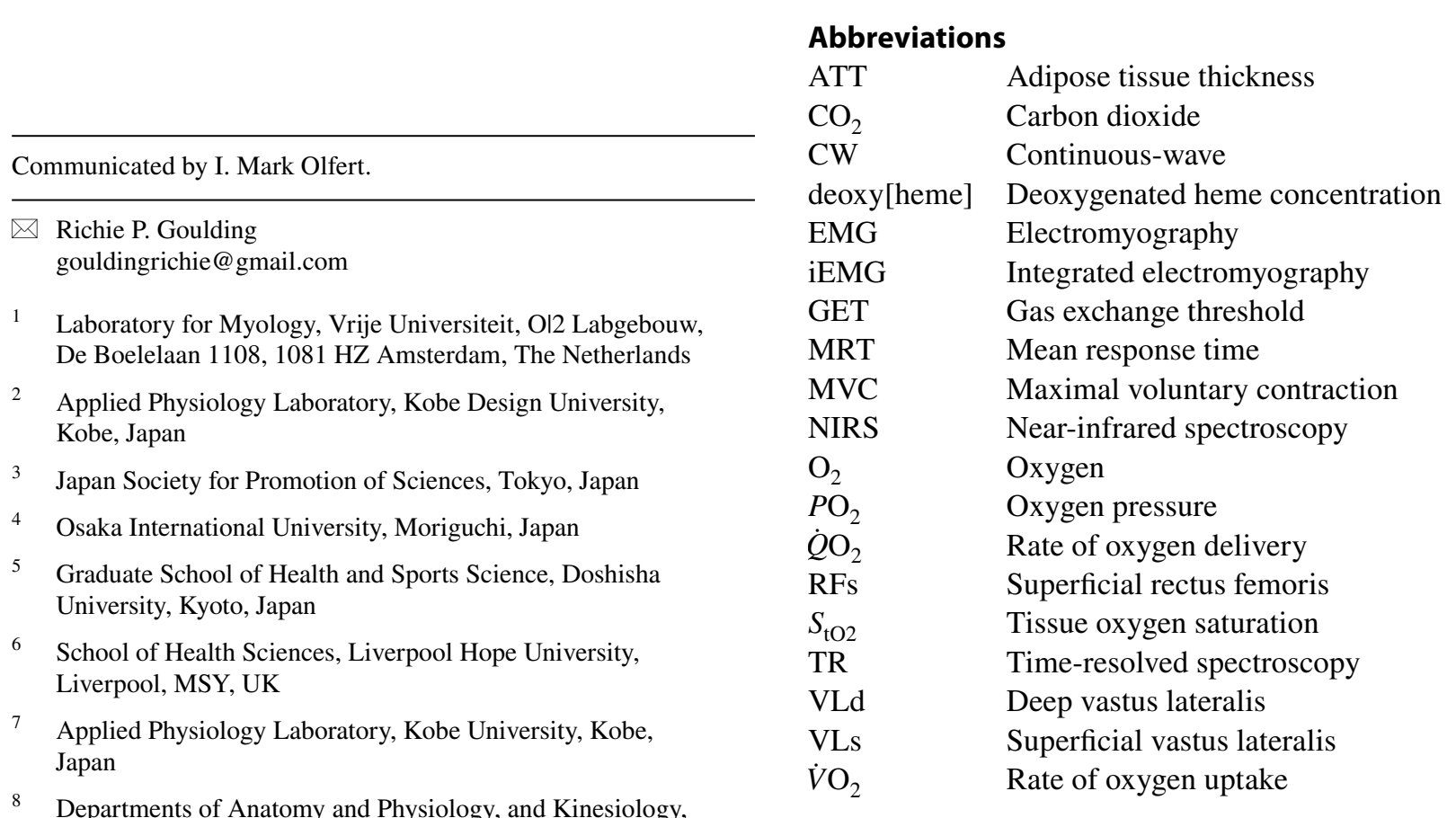



$\dot{V} \mathrm{O}_{2 \text { peak }}$
Highest 20-s rate of oxygen uptake attained during incremental exercise $\mathrm{WR}_{\text {peak }}$ Highest work rate value attained during incremental exercise

\section{Introduction}

Understanding the mechanisms governing the response of oxygen uptake $\left(\mathrm{VO}_{2}\right)$ to exercise is scientifically important as it is a major determinant of exercise tolerance both in health and disease (Bailey et al. 2009; Burnley et al. 2011; Goulding et al. 2017, 2018a, b, 2019a, b, 2020c; Murgatroyd et al. 2011; Rossiter 2010; Whipp and Ward 1992). In this respect, ramp incremental exercise testing facilitates the determination of multiple parameters of aerobic function in a single visit (Whipp et al. 1981) and has thus been used extensively to investigate the relationships between muscle $\mathrm{O}_{2}$ delivery $\left(\dot{Q} \mathrm{O}_{2}\right), \dot{V} \mathrm{O}_{2}$, and fractional $\mathrm{O}_{2}$ extraction both at the systemic level (Faulkner et al. 1977) and within the periphery (Boone et al. 2009, 2010; Ferreira et al. 2007b; Murias et al. 2013).

Investigations utilizing near-infrared spectroscopy (NIRS) to noninvasively determine the balance of $\dot{Q}$ $\mathrm{O}_{2}$-to- $\dot{V} \mathrm{O}_{2}$ within the microcirculation have revealed an approximately sigmoidal or "double-linear" response of deoxygenation (i.e. deoxygenated hemoglobin + myoglobin; deoxy[heme]) during ramp exercise, leading some to suggest a nonlinear relationship between $\dot{Q} \mathrm{O}_{2}$ and $\dot{V} \mathrm{O}_{2}$ within the muscle microcirculation (Boone et al. 2009, 2010; Ferreira et al. 2007b; Spencer et al. 2012). Interventions that perturb the normal balance of $\dot{Q} \mathrm{O}_{2}$-to- $\dot{V} \mathrm{O}_{2}$ during incremental exercise have the capacity to further our understanding of this relationship and its role in task failure. In this regard, supine exercise reduces $\dot{Q} \mathrm{O}_{2} / \dot{V} \mathrm{O}_{2}$ via a loss of perfusion pressure due to the absence of the hydrostatic gradient effect in this position (DiMenna et al. 2010a; Jones et al. 2006; Koga et al. 1999). Accordingly, supine exercise increases the slope of the muscle deoxy[heme] response to ramp exercise when compared to the upright position, at least within the superficial vastus lateralis (VLs) muscle (DiMenna et al. 2010a). This behavior was associated with a greater slope of $\dot{V O}_{2}$ vs. work rate during the latter portion of the ramp during supine compared to upright exercise, a finding interpreted as the supine posture exerting a greater effect on oxidative metabolism at higher intensities where type II fiber recruitment is expected to be accentuated (DiMenna et al. 2010a). However, that investigation only examined a single, superficial portion of the VL muscle (DiMenna et al. 2010a) using continuous-wave (CW-) NIRS (which is limited to relative changes in [heme] chromophores), and as such the extent to which these findings apply to other regions of the exercising muscle mass remains unknown.

In contrast, both phase-modulation and time-resolved (TR-) NIRS devices measure absolute values of [heme] chromophores and possess the capacity for multisite sampling (Koga et al. 2011). Such measurements have shown deoxy[heme] responses to be spatially and temporally heterogeneous during ramp cycle exercise (Chin et al. 2011; Okushima et al. 2015, 2016, 2020). In particular, the deep muscle appears to possess a greater $\dot{Q} \mathrm{O}_{2} / \dot{V} \mathrm{O}_{2}$ ratio during exercise when compared to superficial muscle (Koga et al. 2015,2017,2019; Okushima et al. 2015). It has been suggested that differences between deep and superficial muscle may emanate, in part, from higher blood flow (Heinonen et al. 2010; Kalliokoski et al. 2000, 2003) and a greater proportion of more highly oxidative type I fibres in the deep muscle (Johnson et al. 1973; Lexell et al. 1983). Consideration of both between- and within-muscle heterogeneity is, therefore, necessary to gain a more complete understanding of local control of $\dot{Q} \mathrm{O}_{2} / \dot{V} \mathrm{O}_{2}$ relationships, and thus the events that conspire to bring about task failure during ramp incremental exercise.

Our recent findings of increased amplitude of the deoxy[heme] in the supine position in response to heavyintensity, constant-work rate exercise in both deep and superficial muscle suggest that the impairment in $\dot{Q} \mathrm{O}_{2} / \dot{V}$ $\mathrm{O}_{2}$ brought about by the supine intervention is apparent across the exercising muscle mass (Goulding et al. 2020b). However, it remains unknown to what extent these effects differ as a function of exercise intensity and/or fiber type. Assessment of deep versus superficial muscle (i.e., deep VL [VLd] vs. VLs), along with muscles differing in activation patterns (assessed using electromyography; EMG) and $\dot{Q} \mathrm{O}_{2} / \dot{V} \mathrm{O}_{2}$ (i.e., VLs vs. superficial rectus femoris [RFs]) in response to supine ramp exercise will, therefore, provide a more complete picture surrounding the events that precipitate exercise intolerance in this position.

The aim of the present study was, therefore, to examine the influence of posture (i.e., supine vs. upright) on the muscle deoxy[heme], total[heme] (i.e., deoxy- + oxygenated[heme]), and muscle activation (assessed via EMG) responses to ramp exercise and their heterogeneity within and among the locomotor muscles. In accordance with our recent study (Goulding et al. 2020b), we hypothesized that supine exercise would: 1) increase the absolute values and slopes of the deoxy[heme] responses to exercise; and 2) that this profile would be invariant across muscles and exercise intensities. In assessing multiple sites using combined high-precision TR-NIRS and EMG measurements, we sought to gain insight into the physiological mechanisms underpinning earlier task failure during supine ramp exercise. 


\section{Methods}

\section{Participants}

Eleven healthy male participants (age: $22 \pm 4$ years; height $175 \pm 7 \mathrm{~cm}$; weight $69 \pm 9 \mathrm{~kg}$ ) volunteered to take part, providing written informed consent. The experiment was approved by the Human Subjects Committee of Kobe Design University and conformed to the Declaration of Helsinki, with the exception of registration in a database. Participants were instructed to avoid alcohol and strenuous exercise $24 \mathrm{~h}$ prior to each visit, not to consume caffeine on the same day as a scheduled laboratory visit and to arrive at least $3 \mathrm{~h}$ postprandial. Each test was scheduled at the same time of day $\pm 2 \mathrm{~h}$, with at least $48 \mathrm{~h}$ between visits.

\section{Experimental overview}

All tests took place in a temperature-controlled laboratory that was maintained at $25 \pm 1{ }^{\circ} \mathrm{C}$ and $50 \pm 10 \%$ humidity. Each participant visited the laboratory on two separate occasions. All exercise tests were conducted using an electronically braked cycle ergometer (75XL-III; Combi, Tokyo, Japan). A custombuilt metal frame with an adjustable chair was attached to the back of the ergometer, on which participants lay flat during the supine exercise tests to enable supine cycling. Handles were available to grip during the supine exercise tests to prevent rear movements when forces were applied to the pedals. Distance from the iliac crest to the crankshaft was recorded in the first visit and replicated in the subsequent visit in the second posture. Throughout all exercise tests, cadence was strictly maintained at $60 \mathrm{rpm}$ using an audible metronome. The order of upright and supine exercise tests was counterbalanced. A familiarization session was conducted in the supine position to familiarize participants with the unusual mode of cycling and minimize intraindividual variation in cycling gait throughout the test.

Participants performed ramp incremental tests in the upright and supine positions on separate days. Each test was preceded by 2-min quiet rest on the ergometer and 4-min baseline cycling at $20 \mathrm{~W}$. This was followed by a ramped, linear increase in work rate of $20 \mathrm{~W} / \mathrm{min}$ (i.e., $1 \mathrm{~W}$ increase every $3 \mathrm{~s}$ ) until the participant could no longer maintain the required cadence despite strong verbal encouragement. Task failure was defined as the point at which cadence dropped below $55 \mathrm{rpm}$ for longer than $5 \mathrm{~s}$.

\section{Measurements}

\section{Pulmonary $\mathrm{VO}_{2}$}

Pulmonary gas exchange/ventilation were measured breathby-breath throughout all tests using the same methods previously published in our laboratory (Koga et al. 2019; Okushima et al. 2020). The breath-by-breath gas exchange system (model AE-300S; Minato-Medical, Osaka, Japan) was calibrated according to the manufacturer's instructions before each test. Participants breathed through a low-resistance mouthpiece containing a hot-wire flowmeter for the measurement of inspiratory and expiratory flows and volumes. Inspired and expired gases were sampled continuously from the mouth, and $\mathrm{O}_{2}$ and $\mathrm{CO}_{2}$ fractional concentrations were measured by fast-responding paramagnetic and infrared analyzers, respectively. Gas volume and concentration signals were time aligned to account for the time lag between the signals to calculate $\dot{V} \mathrm{O}_{2}$ on a breath-by-breath basis. Alveolar gas exchange variables were calculated according to the algorithms published by Beaver et al. (1981).

\section{Time-resolved near-infrared spectroscopy}

Continuous non-invasive measurements of absolute deoxy[heme], oxy[heme], total[heme] (i.e., deoxy[heme] + oxy[heme]) and tissue $\mathrm{O}_{2}$ saturation (i.e., oxy[heme]/total[heme] $\times 100, \mathrm{~S}_{\mathrm{tO} 2}$ ) in the RFs and VLs were made using two TR-NIRS devices (TRS-20; Hamamatsu Photonics K.K., Hamamatsu, Japan), while a high-power TR-NIRS device (TRS-20D; Hamamatsu Photonics K.K., Hamamatsu, Japan) was used to measure the same variables in the VLd. The optodes for superficial muscles were placed on the distal sites of the VL and RF parallel to the major axis of the thigh. For deep muscle, the interoptode spacing was $6 \mathrm{~cm}$ and the optodes were placed on the proximal site of the VL muscle. The measurement principles and algorithms employed by the equipment (Koga et al. 2007, 2011; Ohmae et al. 2014), as well as the specific measurement procedures used in our laboratory (Adami et al. 2015; Fukuoka et al. 2015; Koga et al. 2015, 2017, 2019; Okushima et al. 2015, 2016, 2020) have been reviewed in detail elsewhere. Adipose tissue thickness (ATT) was measured at each muscle site during the first visit using B-mode ultrasound (Logiq 400; GE-Yokogawa Medical Systems, Tokyo, Japan). To quantify the influence of ATT on NIRS signals, we employed the correction factor of Bowen et al. (2013) with separate correction factors used for each muscle (Craig et al. 2017).

\section{Surface electromyography}

Surface electromyography (EMG) was measured using electrodes (Bluesensor T-00-S; Ambu, Ballerup; Denmark) 
attached to three separate bipolar EMG sensors connected to a multichannel data acquisition system (MP100; Biopac Systems, Goleta, CA) through an amplifier (Polyam 4; NIHON SANKETU, Osaka, Japan) to estimate muscle activation patterns near the TRS-NIRS optode sites of the VLs and RFs, as previously described (Koga et al. 2019; Okushima et al. 2020). At the beginning of each visit, participants performed three repetitions of maximal voluntary contractions (MVCs) for $7 \mathrm{~s}$ each by extending their leg against a strap attached to a chain, which was in turn attached to a force transducer (T.K.K. 1269f, Takei Scientific Instruments Co., Niigata, Japan), amplifier system (T.K.K. 1268, Takei Scientific Instruments Co., Niigata, Japan) and multichannel data acquisition system (see above), that was hooked onto an immovable bar, while seated upright on a chair (i.e., a joint angle of $90^{\circ}$ ). Participants rested for $3 \mathrm{~min}$ before performing each subsequent MVC. The integrated EMG (iEMG) of the individual muscles was normalized to the highest $1 \mathrm{~s}$ iEMG value observed during the 7-s contraction which produced the highest MVC observed during that visit (i.e., to ensure a true maximum value for each participant on any given day) and expressed as a percentage of MVC.

\section{Data analysis}

$\dot{V} \mathrm{O}_{2}$ peak was defined as the highest $20 \mathrm{~s}$ bin-average value recorded throughout the test. The gas exchange threshold (GET) and mean response time (MRT) were determined as previously described (Boone et al. 2008; Goulding et al. 2017). Peak work rate $\left(\mathrm{WR}_{\text {peak }}\right)$ was defined as the highest work rate attained prior to task failure. All NIRS variables (i.e., deoxy[heme], total[heme], and $S_{\mathrm{tO} 2}$ ) were linearly interpolated to obtain one datum for each NIRS variable every second. The baseline value of each NIRS measurement was calculated as the mean value over the final $30 \mathrm{~s}$ of baseline cycling (i.e., at $20 \mathrm{~W}$ ). The absolute value of each NIRS measurement was then calculated every $60 \mathrm{~s}$ from baseline to maximal exercise for each participant. The value for each NIRS (and iEMG, see below) variable at each $60 \mathrm{~s} \mathrm{time-}$ point (i.e., every $20 \mathrm{~W}$ ) was calculated as a $15 \mathrm{~s}$ average centered on the time at which each specific power output was attained. Maximal NIRS variables were also calculated as the average over the final $15 \mathrm{~s}$ of exercise (i.e., the final $5 \mathrm{~W}$ during the test). Subsequently, NIRS variables determined at specific time points were converted to the power outputs associated with these time points for all further analyses. All NIRS variables were also expressed as a percentage of $\mathrm{WR}_{\text {peak }}$ to facilitate comparisons at the same relative exercise intensity. The decision to plot each NIRS variable as a function of absolute work rate and $\% \mathrm{WR}_{\text {peak }}$ rather than $\dot{V}$ $\mathrm{O}_{2}$ and $\% \dot{V} \mathrm{O}_{2}$ peak was made in light of the fact that local $\dot{V} \mathrm{O}_{2}$ at each muscle site is unknown and the MRT is not constant during ramp incremental exercise (Iannetta et al.
2020; Keir et al. 2015). To account for potential changes in total[heme], and hence blood volume between positions (Goulding et al. 2020a, b), and to aid in the interpretation of crossover interaction effects (see results), the values for each NIRS variable were calculated as a relative change from baseline every $10 \% \mathrm{WR}_{\text {peak }}$ using the same method described above for comparisons at the same absolute work rates. Consistent with previous research from our laboratory (Okushima et al. 2015, 2016), we found that it was not possible to accurately characterize the deoxy[heme] response to ramp exercise using either sigmoidal or double-linear fitting methods in all participants. We, therefore, calculated the magnitude of change in each NIRS variable between each increment in absolute and relative work rate (i.e., every $20 \mathrm{~W}$ as $\Delta$ deoxy- and $\Delta$ total[heme $] / \Delta$ work rate). The raw EMG signals were band-pass filtered $(8-500 \mathrm{~Hz})$ and rectified (Labchart Pro v.8.1.6, ADinstruments, Sydney, NSW, Australia). The integrated EMG (iEMG) signals were normalized to the highest $1 \mathrm{~s}$ value attained during the MVC trial (see above) and expressed as a percentage (\%MVC). The changes in deoxy- and total[heme] between each $10 \%$ increment in $\mathrm{WR}_{\text {peak }}$ from baseline were normalized by the change in iEMG over the same period (i.e., $\Delta \mu \mathrm{M} / \Delta \% \mathrm{MVC}$ ).

\section{Statistical analysis}

All values were expressed as mean \pm SD. Comparisons of $\dot{V}$ $\mathrm{O}_{2}$ parameters and $\mathrm{WR}_{\text {peak }}$ were analyzed by paired-samples $t$ test. All NIRS and iEMG variables were analyzed separately for each muscle (VLd, VLs, and RFs) by two-way repeated measures ANOVA, with main effects of work rate (i.e., every $20 \mathrm{~W}$ from 20 to $180 \mathrm{~W}$ and $\mathrm{WR}_{\text {peak }}$ or every $10 \% \mathrm{WR}_{\text {peak }}$ from 0 to $100 \% \mathrm{WR}_{\text {peak }}$ ) and posture (upright vs. supine). Where significant interaction effects were found, Holm-Sidak adjusted post-hoc comparisons were used to locate these differences. Cohen's $d$ and partial-eta squared $\left(\eta_{\mathrm{p}}^{2}\right)$ were also calculated as measures of effect size. Statistical software (SigmaPlot 13.0, Systat Software, San Jose, CA) was used for all statistical analyses; figures were produced using GraphPad Prism (ver. 7.02, GraphPad Software, San Diego, USA). Significance was declared when $P<0.05$.

\section{Results}

Supine exercise resulted in a reduced $\dot{V} \mathrm{O}_{2}$ peak (supine: $46 \pm 4$, upright: $53 \pm 6 \mathrm{~mL} \cdot \mathrm{kg}^{-1} \cdot \mathrm{min}^{-1}, d=1.50, P<0.001$ ), GET (supine: $25 \pm 4$, upright: $29 \pm 5 \mathrm{~mL} \cdot \mathrm{kg}^{-1} \cdot \mathrm{min}^{-1}$, $d=1.40, P<0.001$ ), and $\mathrm{WR}_{\text {peak }}$ (supine: $241 \pm 33$, upright: $293 \pm 38 \mathrm{~W}, d=1.93, P<0.001$ ) when compared to upright exercise. Moreover, the MRT was greater in the supine compared to the upright position (supine: $78 \pm 16$, upright: $65 \pm 20 \mathrm{~s}, d=0.86, P=0.009)$. 
In the VLd, deoxy[heme] $\left(\eta_{\mathrm{p}}^{2}=0.0024, P=0.92\right)$ and total[heme] $\left(\eta_{\mathrm{p}}^{2}=0.0012, P=0.86\right)$ did not differ between positions at a given absolute work rate or as a relative change from baseline $\left(\eta_{\mathrm{p}}^{2}=0.0096-0.022\right.$, both $P>0.05$, Fig. 1). Thus, VLd $\Delta$ deoxy[heme $] / \Delta$ work rate and $\Delta$ total[heme] $/ \Delta$ work rate were invariant between positions $\left(\eta_{\mathrm{p}}^{2}=0.029-0.11\right.$, both $\left.P>0.05\right)$. Consideration of individual responses revealed evidence of interindividual heterogeneity in the ability to defend deoxy[heme] during supine versus upright exercise in the VLd, and representative responses from 3 individuals are illustrated in Fig. 2. In the majority of participants ( $n=7$ out of 11, Fig. 2, Panel A), deoxy[heme] was maintained at concentrations not different from those observed during upright exercise. However, in two participants, there was a greater degree of deoxygenation in the supine versus upright position in the VLd (Fig. 2, Panel b), whereas in the remaining two, no increase in deoxygenation occurred in either position (Fig. 2, Panel c).

In the VLs, deoxy[heme] was lower at $20 \mathrm{~W}$ but greater at $180 \mathrm{~W}$ and maximal exercise in the supine compared to the upright position (i.e., crossover interaction effect, $\eta_{\mathrm{p}}^{2}=0.50, P<0.001$, Fig. 3, Panel a). $\Delta$ deoxy[heme $] / \Delta$ work rate was greater at $120 \mathrm{~W}$, and every work rate thereafter until maximal exercise in the supine position $\left(\eta_{\mathrm{p}}^{2}=0.27\right.$, $P<0.001)$. When expressed as a relative change from baseline, deoxy[heme] was greater from 50 to $100 \% \mathrm{WR}_{\text {peak }}$ in the supine compared to the upright position $\left(\eta^{2}{ }_{\mathrm{p}}=0.40\right.$,
$P<0.001$, Fig. 3, Panel B). Total[heme] and $\Delta$ total[heme]/ $\Delta$ work rate did not differ between supine and upright exercise when expressed as a function of either absolute work rate or as a relative change from baseline $\left(\eta_{\mathrm{p}}^{2}=0.006-0.01\right.$, all $P>0.05$, Fig. 3, Panels c, d). iEMG was lower in the VLs between 20 and $100 \mathrm{~W}$ and at maximal exercise (maximal exercise; supine: $35 \pm 9$, range $25-55$, upright: $39 \pm 11$, range $16-55 \% \mathrm{MVC})$ in the supine position $\left(\eta_{\mathrm{p}}^{2}=0.24, P=0.016\right.$, Fig. 4, Panel a). The overall change in deoxy- $\left(\eta_{\mathrm{p}}^{2}=0.35\right.$, $P=0.019)$ and total[heme] $\left(\eta_{\mathrm{p}}^{2}=0.35, P=0.011\right)$ normalized by iEMG (i.e., $\Delta \mu \mathrm{M} / \Delta \% \mathrm{MVC}$ at maximal exercise) was greater in the supine position in the VLs.

For the RFs, deoxy[heme] was greater at $160 \mathrm{~W}, 180 \mathrm{~W}$, and maximal exercise $\left(\eta_{\mathrm{p}}^{2}=0.27, P<0.001\right)$ in the supine position, and when expressed as a relative change from baseline, deoxy[heme] was greater from 70 to $100 \% \mathrm{WR}_{\text {peak }}$ $\left(\eta_{\mathrm{p}}^{2}=0.33, \mathrm{P}<0.001\right.$, Fig. 5, Panel a, b). Total[heme] was greater in the supine position at $120 \mathrm{~W}$ and every work rate thereafter up to maximal exercise $\left(\eta_{\mathrm{p}}^{2}=0.38\right.$, $P<0.001$, Fig. 5, Panel c), and when expressed as a relative change from baseline, total[heme] was greater from 60 to $100 \% \mathrm{WR}_{\text {peak }}\left(\eta_{\mathrm{p}}^{2}=0.28, P<0.001\right.$, Fig. 5, Panel d). $\Delta$ deoxy $[$ heme $] / \Delta$ work rate and $\Delta$ total[heme] $/ \Delta$ work rate were greater between each increment in absolute work rate in the supine position $\left(\eta_{\mathrm{p}}^{2}=0.014-0.13\right.$, both $\left.P<0.05\right)$. iEMG was greater in the RFs from 80 to $180 \mathrm{~W}$ in the supine position $\left(\eta_{\mathrm{p}}^{2}=0.24, P=0.016\right)$, but not different at maximal
Fig. 1 Group mean deoxy[heme] (a, b) and total[heme] $(\mathbf{c}, \mathbf{d})$ responses to ramp incremental cycle exercise as a function of both absolute power output (a, c) and as a relative change from the baseline value, plotted as a percentage of the peak work rate attained during the test (b, d) in the deep vastus lateralis (VLd). Error bars represent SD. No differences were observed between postures

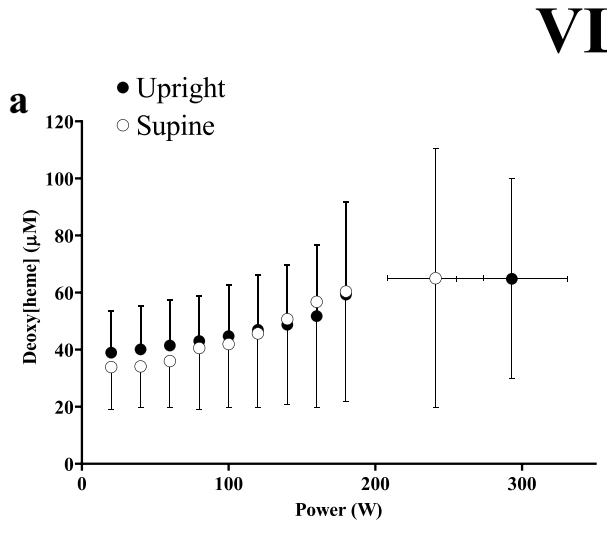

c

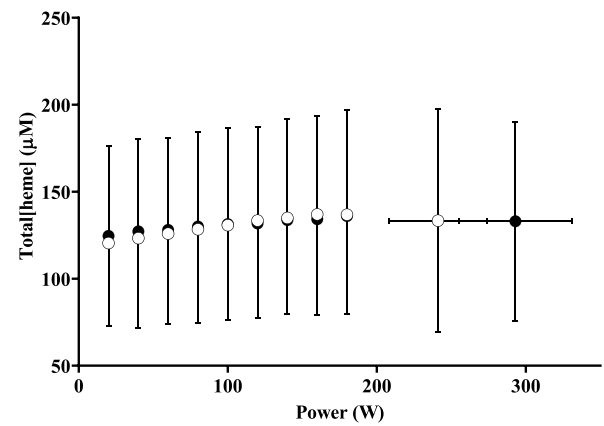

b

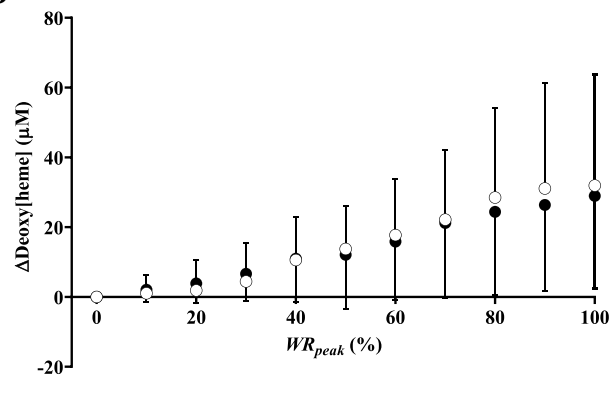

d

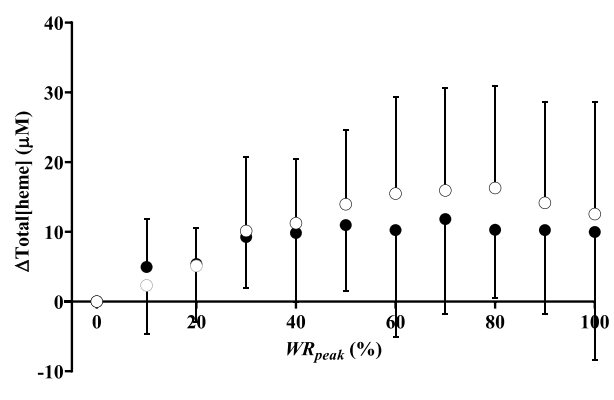




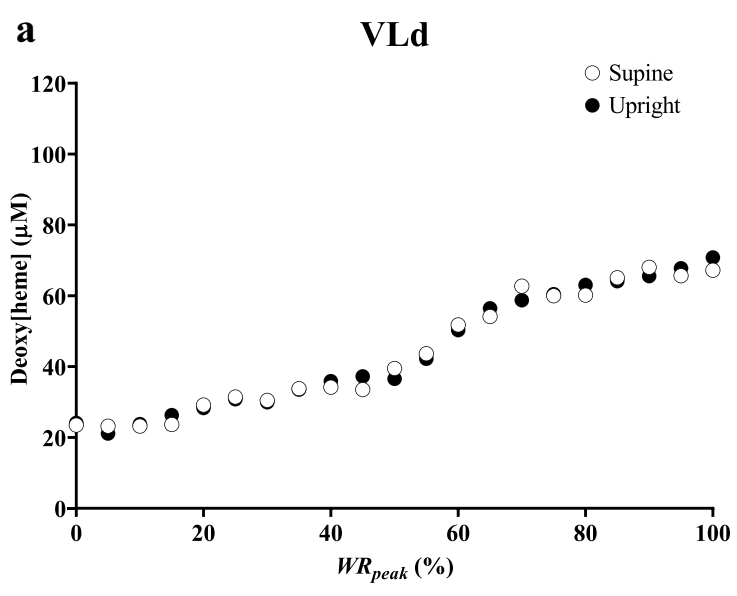

b

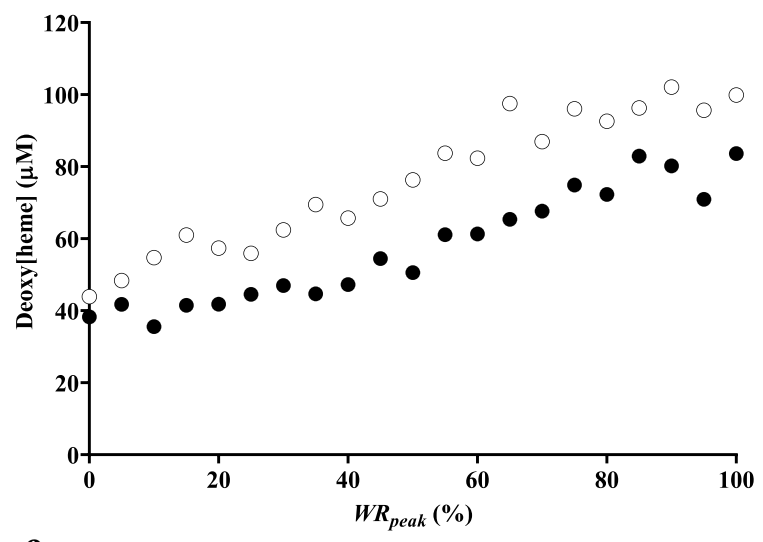

c

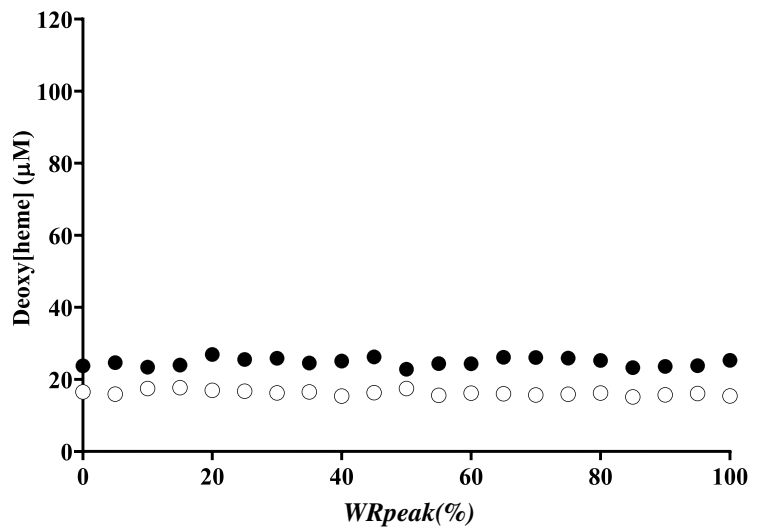

Fig. 2 Illustration of the 3 categories of responses of deoxy[heme] to ramp incremental exercise in the upright and supine positions observed in the deep vastus lateralis in 3 representative participants. See results section of the text for further details

exercise (supine: $27 \pm 11$, range $15-50$, upright: $27 \pm 14 \%$ MVC, range 11-47, Fig. 4, Panel b). The overall change in deoxy- $\left(\eta_{\mathrm{p}}^{2}=0.35, P=0.019\right)$ and total[heme $]\left(\eta_{\mathrm{p}}^{2}=0.35\right.$, $P=0.011$ ) normalized by iEMG was greater in the supine position in the RFs.

\section{Discussion}

The principal original finding of the present investigation, consistent with our first hypothesis, was that ramp cycle exercise performed in the supine position resulted in greater absolute values and slopes of the deoxy[heme] responses in the VLs and RFs (i.e., as $\Delta$ deoxy[heme]/ $\Delta$ work rate and as a relative change from baseline) when compared to upright exercise. However, in contrast to our second hypothesis, the effects of the supine posture were highly dependent upon exercise intensity and muscle site. For instance, the effects of supine posture on muscle deoxygenation responses in the superficial muscle (i.e., VLs and RFs) manifested to a greater extent at higher work rates. Moreover, there were no differences between upright and supine exercise in the VLd. That the effects of supine exercise were observed to be specific to muscle region, depth, and exercise intensity might suggest that these differences can be explained by differential effects of impaired perfusion pressure on muscle fiber pools possessing inherently different vascular and metabolic control properties.

\section{Comparisons with previous work}

The present study was designed, in part, to address questions generated by DiMenna et al. (2010a), who demonstrated that the slope of the sigmoid function used to characterize muscle deoxygenation was increased by $\sim 100 \%$ in the supine position when expressed as a function of absolute work rate and by $\sim 70 \%$ when normalized to $\mathrm{WR}_{\text {peak }}$ (DiMenna et al. 2010a). However, that study utilized CW-NIRS, which assumes a fixed scattering coefficient and optical path length throughout data collection. These assumptions are violated during exercise, and as such, CW-NIRS instruments overestimate changes in heme chromophores during ramp exercise (Ferreira et al. 2007a). Ferreira et al. (2007a) also demonstrated that, in some subjects, the change in the reduced scattering coefficient during ramp exercise was related to the increase in total[heme] during the protocol. This latter consideration is particularly pertinent within the context of supine exercise, where we have recently demonstrated that larger changes in total[heme] occur in the transition from rest to exercise compared with the upright position (Goulding et al. 2020a, b). Indeed, in the present study, changes in muscle deoxy[heme] for a given change in work rate between upright and supine exercise in the VLs were more modest than those reported by DiMenna et al. (2010a); with the change in deoxy[heme] for a given change in work rate being increased by $\sim 60 \%$ in the supine position when 
Fig. 3 Group mean deoxy[heme] $(\mathbf{a}, \mathbf{b})$ and total[heme] $(\mathbf{c}, \mathbf{d})$ responses to ramp incremental cycle exercise as a function of both absolute power output (a, c) and as a relative change from the baseline value, plotted as a percentage of the peak work rate attained during the test $(\mathbf{b}, \mathbf{d})$ in the superficial vastus lateralis (VLs). Error bars represent SD. *Significant difference between postures at the same absolute or relative work rate $(P<0.05)$

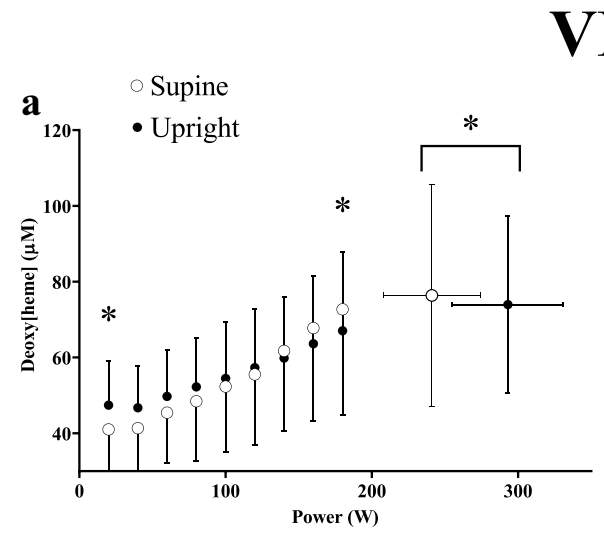

c

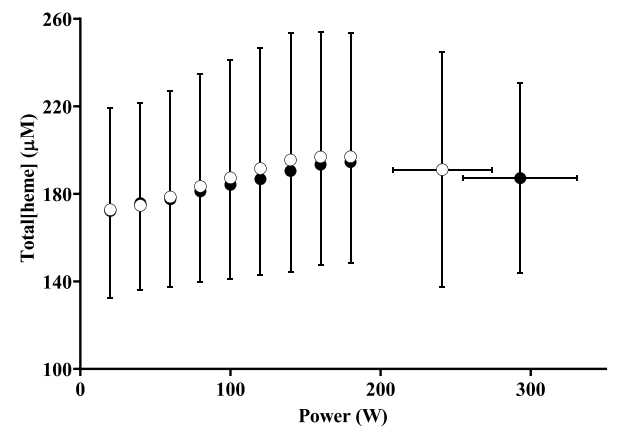

VLs

b

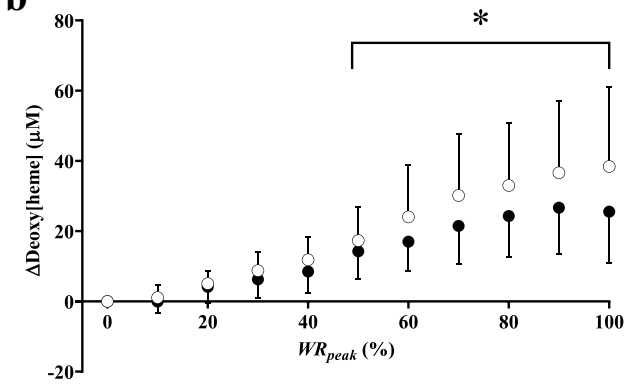

d

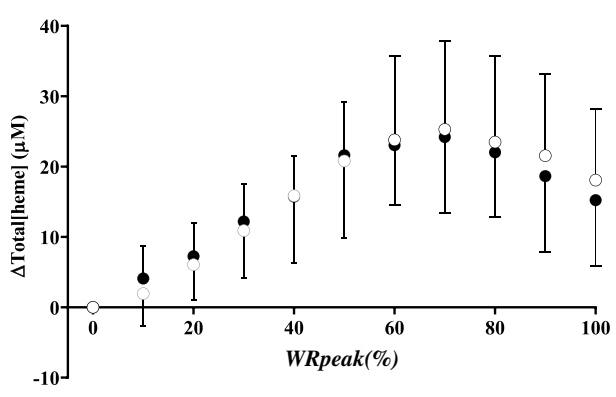

expressed in absolute terms and $\sim 50 \%$ when normalized by $\mathrm{WR}_{\text {peak }}$. Hence, the present findings highlight the need for caution when interpreting the results of studies that have utilized CW-NIRS to interpret the impact of an intervention on muscle $\mathrm{O}_{2}$ extraction.

\section{Posture-induced changes in superficial muscle}

Deoxy[heme] was lower in the VLs during baseline cycling at $20 \mathrm{~W}$ during supine compared to upright exercise, a finding likely explained by the lower iEMG (and presumably, therefore, local $\dot{V} \mathrm{O}_{2}$ ) in the VLs between 20 and $100 \mathrm{~W}$ in the supine position. Above $100 \mathrm{~W}$ there were no differences in muscle activation between positions, and as a result $\Delta$ deoxy $[$ heme $] / \Delta$ work rate was augmented in the supine position above $120 \mathrm{~W}$ or $50 \% \mathrm{WR}_{\text {peak }}$ (Fig. 3, Panels $a$ and $b)$. The impact of supine exercise on muscle deoxygenation in the VLs was most evident at the greatest intensities attained: values for deoxy[heme] were only greater in the supine position at $180 \mathrm{~W}$ and maximal exercise which occurred despite lower muscle activation at maximal exercise in this muscle (Fig. 4a). Moreover, deoxy[heme] normalized by iEMG (i.e., $\Delta \mu \mathrm{M} / \Delta \% \mathrm{MVC}$ ) at maximal exercise in the supine position was greater when compared to upright exercise. In the RFs, $\Delta$ deoxy [heme]/ $\Delta$ work rate was greater throughout exercise in the supine compared to the upright position, suggesting that impairments in the $\dot{Q} \mathrm{O}_{2} / \dot{V} \mathrm{O}_{2}$ ratio necessitated higher fractional $\mathrm{O}_{2}$ extractions to support any given change in external work rate in this muscle. Moreover, in the supine position, iEMG in the RFs increased above that for upright exercise at work rates above $80 \mathrm{~W}$. This was followed by increased absolute values of deoxy[heme] from $160 \mathrm{~W}$ to maximal exercise. Collectively, therefore, the present findings suggest that the supine posture exerted its greatest effects on superficial muscle (i.e., the RFs and VLs) at higher intensities where type II fiber recruitment would be expected to dominate (Gollnick et al. 1974; Krustrup et al. 2004). These findings are in broad agreement with the earlier work of DiMenna et al. (2010a), and further those findings by highlighting their muscle-region and depth-specificity.

In the RFs, $\Delta$ total[heme]/ $\Delta$ work rate was increased throughout exercise in the supine position, leading to an elevated total[heme] above $120 \mathrm{~W}$. These observations suggest that a primary mechanism by which the RFs achieved greater fractional $\mathrm{O}_{2}$ extraction at greater work rates in the supine position was via elevated diffusive $\mathrm{O}_{2}$ conductance consequent to increased microvascular [hematocrit]. Indeed, capillary red blood cell velocity increases more with contractions in less oxidative rat muscles (Dawson et al. 1987) and faster red blood cell velocity is associated with a higher capillary hematocrit (Kindig et al. 2002). We have previously demonstrated that the RFs is more dependent on $\mathrm{O}_{2}$ extraction for a given degree of muscle activation when compared to the VLs (Goulding et al. 2020b), consistent 


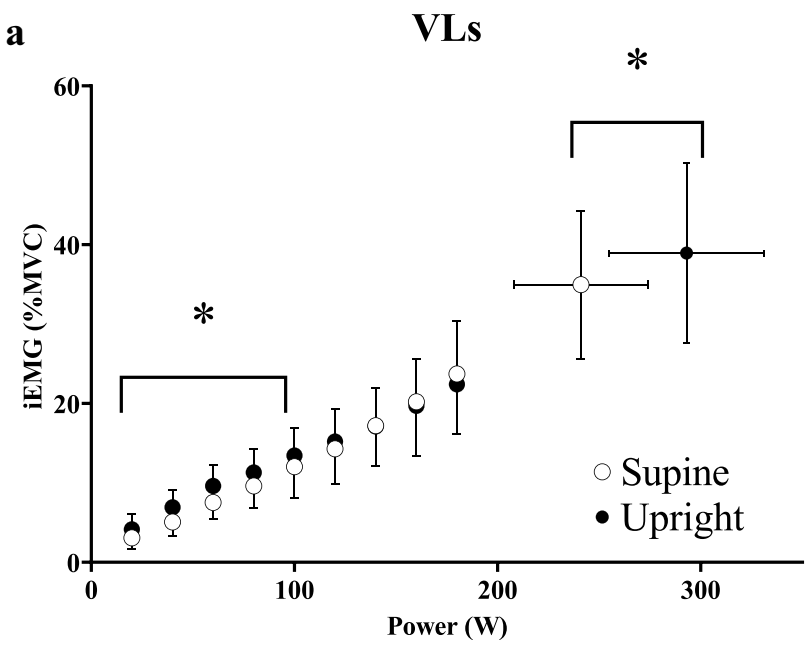

b

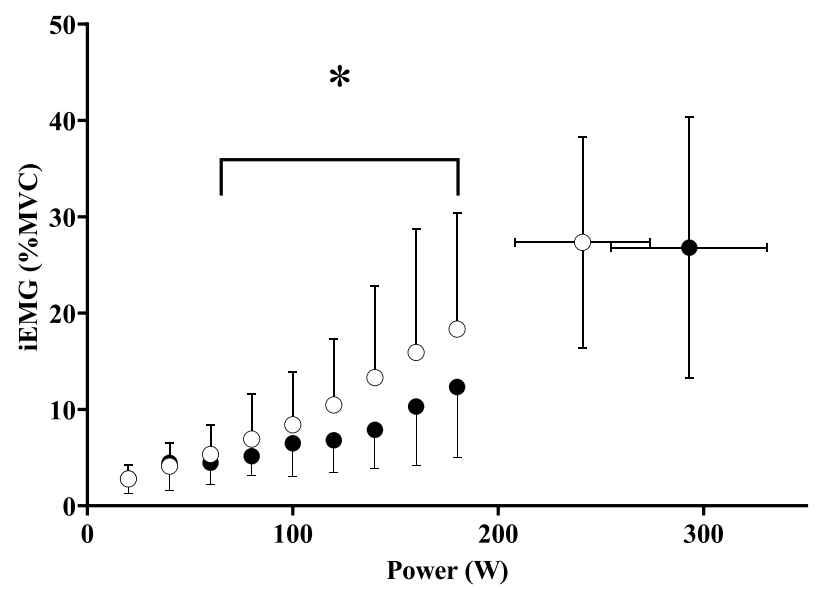

Fig. 4 Group mean iEMG profiles in the VLs (a) and RFs (b) as a function of both absolute power output. Error bars represent SD. *Significant difference between postures at the same absolute or relative work rate $(P<0.05)$

with what would be expected in a muscle consisting of a greater proportion of higher-order, less oxidative fibers (Dahmane et al. 2005; Johnson et al. 1973). Therefore, the findings in the RFs herein might reflect that which would be expected from the recruitment of a muscle comprised of a greater proportion of type II muscle fibers that are inherently more sensitive to reductions in muscle perfusion pressure (i.e., closer to their respective $\mathrm{O}_{2}$ delivery "tipping points"; DiMenna et al. 2010b; Goulding et al. 2020a, b; Poole et al. 2007, 2008; Poole and Jones 2012), such as that brought about by supine exercise.

\section{Posture-induced changes in deep muscle}

In the VLd, neither deoxy[heme] nor total[heme] differed between positions either at a given absolute work rate or as a relative change from baseline. In addition, $\Delta$ deoxy[heme]/ $\Delta$ work rate and $\Delta$ total[heme] $/ \Delta$ work rate did not differ between body positions in the VLd. Hence, in the present study and in stark contrast with superficial muscle, deep muscle was not impacted by changes in muscle perfusion pressure induced by the supine position. There are multiple explanations for this finding. For instance, deep muscles receive far greater rates of blood flow during exercise when compared to superficial muscles (Heinonen et al. 2015, 2010; Laughlin and Armstrong 1982; Piiper et al. 1985) and are comprised of a relatively greater portion of oxidative type I fibers (Dahmane et al. 2005; Johnson et al. 1973). These fibers are known to operate at higher $\dot{Q} \mathrm{O}_{2} / \mathrm{VO}_{2}$ ratios and demonstrate less pronounced falls in microvascular $\mathrm{PO}_{2}$ at the onset of contractions when compared to less oxidative muscle (Behnke et al. 2003; McDonough et al. 2005). Hence, the greater ability of the VLd to defend $\dot{Q} \mathrm{O}_{2} / \dot{V} \mathrm{O}_{2}$ against changes in perfusion pressure induced by the supine position may be related to this muscle region consisting of a greater proportion of highly oxidative type I fibers with greater rates of blood flow, a higher pressure head for bloodto-myocyte $\mathrm{O}_{2}$ flux, and greater vasodilatory control sensitivity (Behnke et al. 2003; Laughlin et al. 2012; McDonough et al. 2005).

The present findings are in contradiction with our recent finding of an increased muscle deoxy[heme] amplitude in the VLd during heavy supine constant work rate exercise (Goulding et al. 2020b). One explanation for this discrepancy may be the fact that muscle deoxy[heme] kinetics are slower during supine compared to upright exercise (Goulding et al. 2020b), and hence the non-steady-state conditions of ramp exercise in the present study may not have allowed sufficient time for steady-state $\dot{Q} \mathrm{O}_{2} / \dot{V} \mathrm{O}_{2}$ reductions to become manifest in the VLd (Boone et al. 2010). However, in our previous study muscle deoxy[heme] kinetics were also slower in the superficial muscle (VLs and RFs), and in the present study an impaired $\dot{Q} \mathrm{O}_{2} / \dot{V} \mathrm{O}_{2}$ response was observed during supine ramp exercise in both the RFs and VLs. Hence, an alternative explanation is required.

Individual differences between the two groups of subjects, perhaps in part related to differences in muscle fiber composition, may explain the divergent findings between the present and our previous studies (Goulding et al. 2020a, b). For instance, as shown in Fig. 2, there was evidence of interindividual heterogeneity in the deoxy[heme] responses to exercise in both positions in deep muscle. The factors that enable some subjects to defend $\dot{Q} \mathrm{O}_{2} / \dot{V} \mathrm{O}_{2}$ during supine exercise in the VLd more effectively than others are presently unclear; for example, the differences in deoxy[heme] between positions were not related to $\dot{V} \mathrm{O}_{2}$ peak (data not shown). However, it is clear based on the present data that increased fractional $\mathrm{O}_{2}$ extraction in the supine position is not an obligatory response in the deep muscle. Hence, at 
Fig. 5 Group mean deoxy[heme] $(\mathbf{a}, \mathbf{b})$ and total[heme] $(\mathbf{c}, \mathbf{d})$ responses to ramp incremental cycle exercise as a function of both absolute power output $(\mathbf{a}, \mathbf{c})$ and as a relative change from the baseline value, plotted as a percentage of the peak work rate attained during the test $(\mathbf{b}, \mathbf{d})$ in the superficial rectus femoris (RFs). Error bars represent SD. *Significant difference between postures at the same absolute or relative work rate $(P<0.05)$.

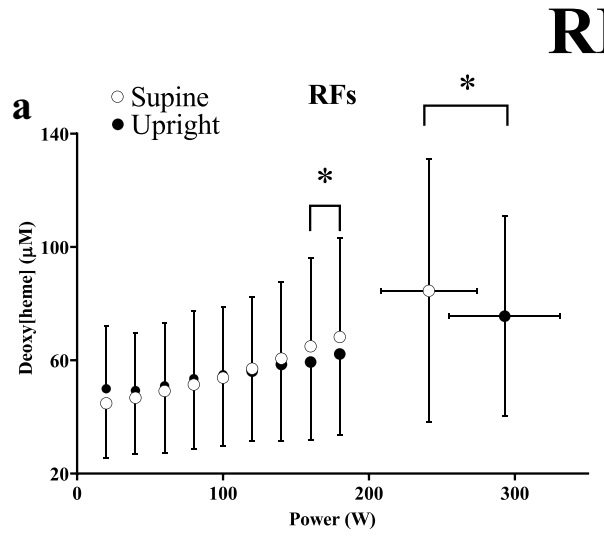

RFs

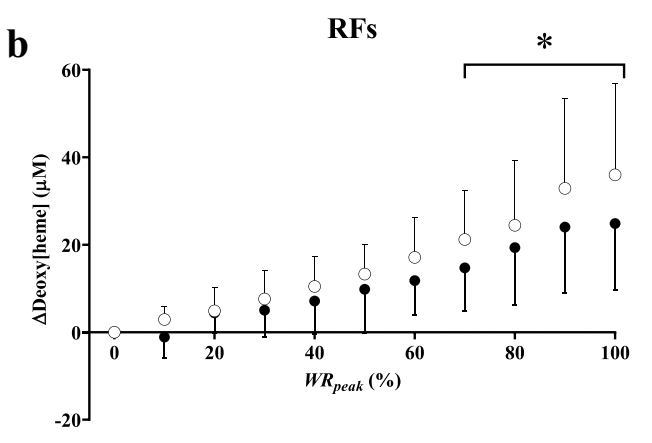

c

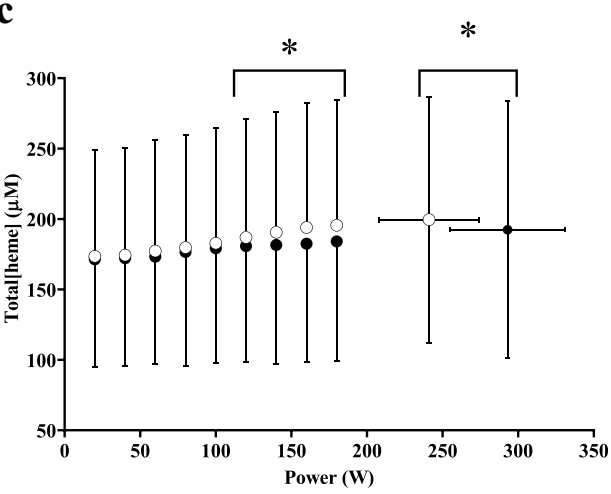

d

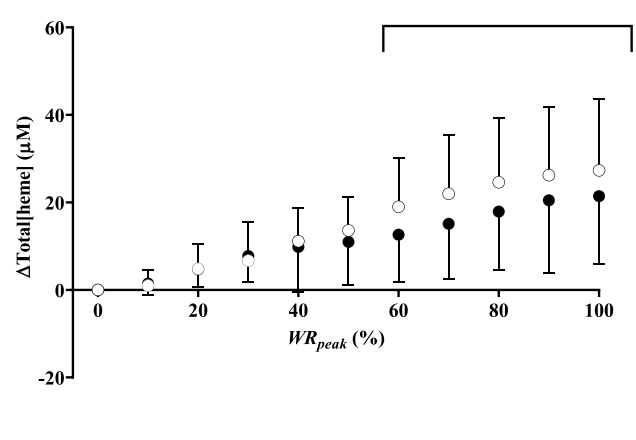

least in the majority of participants, the causes of the earlier task failure in the supine position noted herein (insofar as they involve $\mathrm{O}_{2}$ delivery-utilization matching) are primarily confined to superficial muscle.

\section{Mechanistic bases for reduced exercise tolerance and $\mathrm{VO}_{2}$ peak in the supine position}

$\mathrm{O}_{2}$ availability is known to modulate muscle recruitment patterns, with lower $\mathrm{O}_{2}$ availability driving greater increases in motor unit activity (Moritani et al. 1992, 1993). In the present study, iEMG was lower in the VLs during supine exercise at moderate work rates, suggesting that the reduced perfusion pressure in the supine position may have modulated muscle recruitment patterns. Indeed, iEMG was greater in the RFs during supine exercise above $80 \mathrm{~W}$, implying that lower $\dot{Q} \mathrm{O}_{2} / \dot{V} \mathrm{O}_{2}$ in the VLs may have necessitated an increased recruitment of the RFs through heavy to severe exercise. Alternatively, the supine posture may have altered muscle recruitment patterns independently of alterations in $\mathrm{O}_{2}$ availability, for instance, due to postural changes and/ or the loss of the gravitational assist for muscle power production. Irrespective of the mechanism by which muscle recruitment patterns were altered during supine exercise, the muscle deoxygenation profiles observed in the RFs above $\sim 160 \mathrm{~W}$ are, in turn, consistent with those expected from a muscle comprised of a greater proportion of less oxidative, higher-order motor units (Behnke et al. 2003; Ferreira et al. 2006; Johnson et al. 1973; McDonough et al. 2005), suggesting that exercise in the supine position necessitated the earlier recruitment of more fatigable type II fibers. That $\Delta$ deoxy[heme $] / \Delta \mathrm{iEMG}$ and $\Delta$ total $[$ heme $] / \Delta \mathrm{iEMG}$ were both increased during supine exercise in the VLs and RFs suggests that supine exercise facilitated the uncoupling of muscle fractional $\mathrm{O}_{2}$ extraction and diffusive $\mathrm{O}_{2}$ transport from muscle recruitment (Okushima et al. 2020), which would be expected under conditions of altered motor unit recruitment. Hence, the lower recruitment of the VLs at moderate work rates during supine exercise precipitated the earlier recruitment of the RFs, which expresses a phenotype consistent with a muscle composed of a greater proportion of type II fibers when compared to the VLs (Jennekens et al. 1971; Johnson et al. 1973; Okushima et al. 2020). Earlier recruitment of the RFs and a lower $\dot{Q} \mathrm{O}_{2} / \dot{V} \mathrm{O}_{2}$ in both the RFs and VLs would thus lead to more precipitous drops in microvascular $P \mathrm{O}_{2}$, intramyocyte $P \mathrm{O}_{2}$ and the intracellular free energy state as work rate increased (Arthur et al. 1992; Behnke et al. 2003; Hogan et al. 1992; Jackman and Willis, 1996; McDonough et al. 2005; Willis and Jackman, 1994; Wilson et al. 1977), leading to earlier task failure (Grassi et al. 2015; Meyer and Foley 2010).

The increased muscle $\mathrm{O}_{2}$ extraction at maximal exercise in superficial muscle in the supine position suggests that muscle diffusive $\mathrm{O}_{2}$ conductance was slightly enhanced in 
this position. Despite this, maximal muscle $\mathrm{O}_{2}$ extraction was unable to increase sufficiently to offset the reduction in maximal muscle $\dot{Q} \mathrm{O}_{2}$ and preserve whole-body $\dot{V} \mathrm{O}_{2}$ peak. Hence, reductions in whole body and regional $\dot{V} \mathrm{O}_{2}$ peak might be explained, in part, via reductions in convective $\mathrm{O}_{2}$ delivery. These concepts are illustrated in Fig. 6, which attempts to explain the contribution of each muscle region studied herein to the reduced whole-body exercise tolerance and $\dot{V} \mathrm{O}_{2}$ peak (Wagner 1996). Briefly, Fick's law of diffusion depicts $\dot{V} \mathrm{O}_{2}$ peak as a function of tissue $\mathrm{O}_{2}$ saturation (assumed to be analogous to mean capillary $\mathrm{PO}_{2}$ for illustrative purposes) with the slope (straight line) representative of muscle $\mathrm{O}_{2}$ diffusive conductance. The intersection of these two lines determines the $\dot{V} \mathrm{O}_{2}$ peak attained. Panel A illustrates that in the $\mathrm{VLd}$, both convective $\mathrm{O}_{2}$ delivery and diffusive $\mathrm{O}_{2}$ conductance were only marginally impacted by supine exercise, and hence $\dot{V} \mathrm{O}_{2}$ peak in this muscle is assumed to remain the same. In panels b and c, the increased slope of the Fick diffusion line in the supine position suggests that these superficial muscles rely preferentially on elevated diffusing capacity and $\mathrm{O}_{2}$ extraction compared to deeper muscle. However, the increases in diffusive $\mathrm{O}_{2}$ conductance were insufficient to offset the reductions in convective $\mathrm{O}_{2}$ delivery brought about via supine exercise, hence $\dot{V}$ $\mathrm{O}_{2}$ peak was reduced.

\section{Limitations}

The depth penetration of NIRS is approximately half of the source-detector separation distance, or around $3 \mathrm{~cm}$ for the VLd in the present investigation. As the pathlength estimated in this fashion is a global mean of an infinite number of possible pathlengths travelled by photons on transit from source to detector, this signal likely includes photons returning from the superficial tissues (i.e., VLs). However, that the majority of the signal from the VLd derives from the deeper tissues is borne out by data from validation studies confirming the depth sensitivity of this system using optical phantoms (Koga et al. 2015), and the consistent observation that deep tissue exhibits markedly altered muscle deoxygenation profiles in response to constant work rate (Koga et al. 2015,2017,2019) and ramp exercise (Okushima et al. 2015). Moreover, given the increase in muscle deoxygenation in the VLs in the supine posture noted herein, any contamination of the NIRS signal from deep muscle with more superficial tissue would be expected to weight our data towards producing an effect of the supine posture on muscle deoxygenation in the VLd. Hence, we are confident that the lack of effect of posture on deoxygenation responses in the VLd observed herein reflects the actual responses in the VLd. Another limitation is the fact that neither the degree of muscle activation nor local $\dot{V} \mathrm{O}_{2}$ were determined in the VLd. Hence, to interpret the dynamic adjustment of $\dot{Q} \mathrm{O}_{2}$ with respect to a

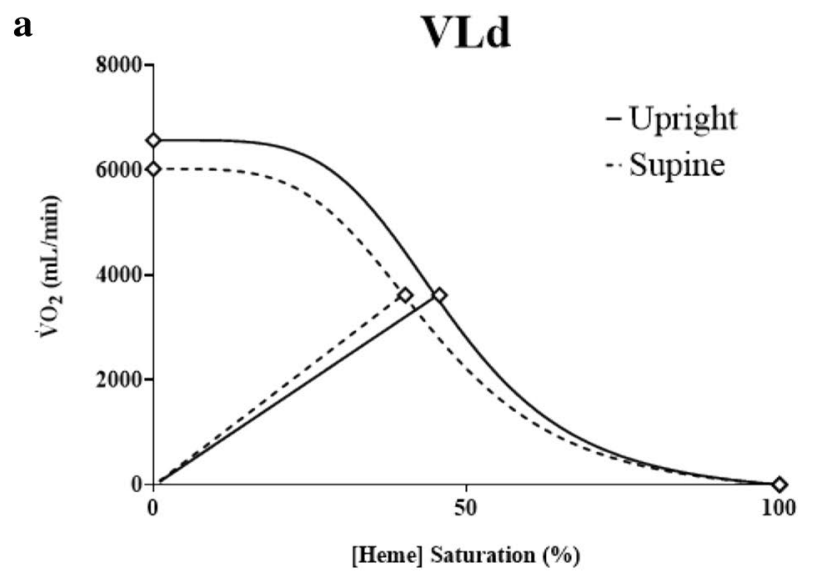

b
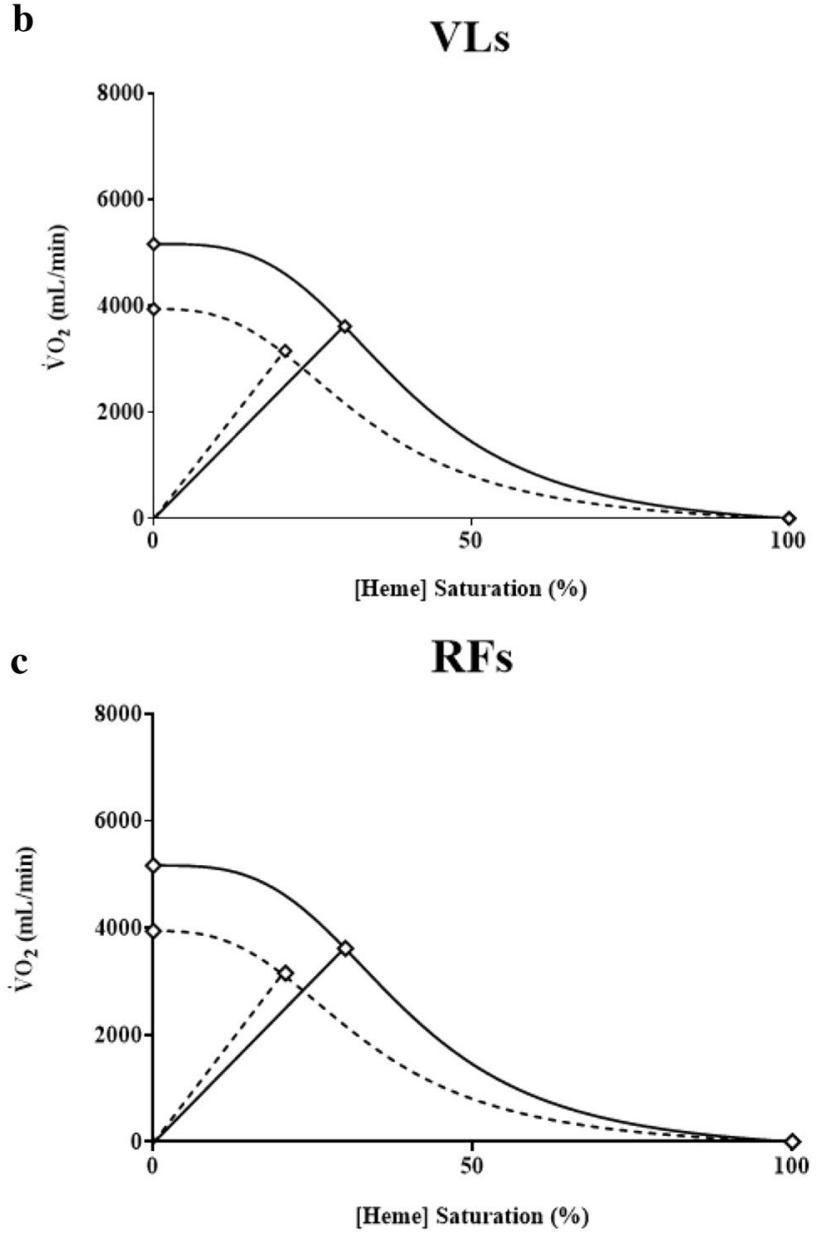

Fig. 6 Wagner plots depicting peak regional muscle $\mathrm{O}_{2}$ uptake as a function of convective $\mathrm{O}_{2}$ delivery (curved lines) vs. tissue $\mathrm{O}_{2}$ saturation (assumed to be analogous to mean capillary $\mathrm{PO}_{2}$ for illustrative purposes) in the VLd (a), VLs (b), and RFs (c). Fick's law of diffusion depicts $\dot{V} \mathrm{O}_{2}$ peak as a function of tissue $\mathrm{O}_{2}$ saturation with the slope (straight line) representative of muscle $\mathrm{O}_{2}$ diffusive conductance. The intersection of these two lines determines the $\dot{V} \mathrm{O}_{2}$ peak attained. Solid lines represent the upright position, dashed lines represent the supine position 
given profile of $\mathrm{O}_{2}$ extraction in deep muscle, a $\dot{V} \mathrm{O}_{2}$ value should be known. However, conducting such measurements in humans during large muscle mass, dynamic exercise is, at present, technically intractable. Further investigations and technological developments (e.g. combined NIRS and diffuse correlation spectroscopy, Quaresima et al. 2019) are, therefore, required to determine how differences in muscle activation and/or local $\dot{V} \mathrm{O}_{2}$ might contribute to the unique $\mathrm{O}_{2}$ transport characteristics of the VLd noted herein.

\section{Conclusion}

In conclusion, marked heterogeneities exist in the strategies by which recruited muscle regions adjust to altered muscle perfusion pressure during supine versus upright ramp incremental cycling exercise. Specifically, deep muscle (i.e., VLd) was able to defend $\dot{Q} \mathrm{O}_{2} / \dot{V} \mathrm{O}_{2}$ in response to reduced muscle perfusion pressure. In contrast, the perturbation of muscle perfusion pressure in the supine position induced profound changes in $\dot{Q} \mathrm{O}_{2} / \dot{V} \mathrm{O}_{2}$ and recruitment patterns in superficial muscles. Specifically, the supine position resulted in a proportionally greater recruitment of the RFs and an expedited rate of muscle deoxygenation at higher intensities in both the RFs and VLs when compared to upright exercise. Hence, in the present study, the factors leading to earlier task failure in the supine position were confined to superficial muscle and exerted their greatest effects at higher intensities where type II fiber recruitment would be expected to dominate.

Author contributions RPG, SM, DCP, TJB and SK were responsible for the design and conception of the work. RPG, DO, SK, YF, and $\mathrm{NK}$, were responsible for data acquisition and analysis, whereas all authors were responsible for the interpretation of the data. RPG drafted the work and all authors revised it critically for important intellectual content, approved the final version to be published, and agree to be accountable for all aspects of the work.

Funding Support for this study was provided by The Japan Society for the Promotion of Science, the Ministry of Education, Science, and Culture of Japan (JSPS Postdoctoral Fellowships for Research in Japan).

Availability of data and material Data are available upon request from the authors.

\section{Compliance with ethical standards}

Conflict of interest The authors declare that there is no conflict of interest associated with this manuscript.

Consent to participate Informed consent was obtained from all individual participants included in the study.
Consent to publish The authors affirm that all human research participants involved in this study provided informed consent for publication of the data contained herein.

Open Access This article is licensed under a Creative Commons Attribution 4.0 International License, which permits use, sharing, adaptation, distribution and reproduction in any medium or format, as long as you give appropriate credit to the original author(s) and the source, provide a link to the Creative Commons licence, and indicate if changes were made. The images or other third party material in this article are included in the article's Creative Commons licence, unless indicated otherwise in a credit line to the material. If material is not included in the article's Creative Commons licence and your intended use is not permitted by statutory regulation or exceeds the permitted use, you will need to obtain permission directly from the copyright holder. To view a copy of this licence, visit http://creativecommons.org/licenses/by/4.0/.

\section{References}

Adami A, Koga S, Kondo N, Cannon DT, Kowalchuk JM, Amano T, Rossiter HB (2015) Changes in whole tissue heme concentration dissociates muscle deoxygenation from muscle oxygen extraction during passive head-up tilt. J Appl Physiol 118:1091-1099. https://doi.org/10.1152/japplphysiol.00918.2014

Arthur PG, Hogan MC, Bebout DE, Wagner PD, Hochachka PW (1992) Modeling the effects of hypoxia on ATP turnover in exercising muscle. J Appl Physiol 73:737-742. https://doi. org/10.1152/jappl.1992.73.2.737

Bailey SJ, Wilkerson DP, Dimenna FJ, Jones AM (2009) Influence of repeated sprint training on pulmonary $\mathrm{O}_{2}$ uptake and muscle deoxygenation kinetics in humans. J Appl Physiol 106:18751887. https://doi.org/10.1152/japplphysiol.00144.2009

Beaver WL, Lamarra N, Wasserman K (1981) Breath-by-breath measurement of true alveolar gas exchange. J Appl Physiol Respir Environ Exerc Physiol 51:1662-1675. https://doi. org/10.1152/jappl.1981.51.6.1662

Behnke BJ, McDonough P, Padilla DJ, Musch TI, Poole DC (2003) Oxygen exchange profile in rat muscles of contrasting fibre types. J Physiol (Lond) 549:597-605. https://doi.org/10.1113/ jphysiol.2002.035915

Boone J, Koppo K, Bouckaert J (2008) The $\mathrm{VO}_{2}$ response to submaximal ramp cycle exercise: Influence of ramp slope and training status. Respir Physiol Neurobiol 161:291-297. https://doi. org/10.1016/j.resp.2008.03.008

Boone J, Koppo K, Barstow TJ, Bouckaert J (2009) Pattern of deoxy $[\mathrm{Hb}+\mathrm{Mb}]$ during ramp cycle exercise: influence of aerobic fitness status. Eur J Appl Physiol 105:851-859. https://doi. org/10.1007/s00421-008-0969-2

Boone J, Koppo K, Barstow TJ, Bouckaert J (2010) Effect of exercise protocol on deoxy $[\mathrm{Hb}+\mathrm{Mb}]$ : incremental step versus ramp exercise. Med Sci Sports Exerc 42:935-942. https://doi. org/10.1249/MSS.0b013e3181c0ecea

Bowen TS, Rossiter HB, Benson AP, Amano T, Kondo N, Kowalchuk JM, Koga S (2013) Slowed oxygen uptake kinetics in hypoxia correlate with the transient peak and reduced spatial distribution of absolute skeletal muscle deoxygenation. Exp Physiol 98:1585-1596. https://doi.org/10.1113/expphysiol .2013 .073270

Burnley M, Davison G, Baker JR (2011) Effects of priming exercise on $V \mathrm{O}_{2}$ kinetics and the power-duration relationship. Med Sci Sports Exerc 43:2171-2179. https://doi.org/10.1249/ MSS.0b013e31821ff26d 
Chin LMK, Kowalchuk JM, Barstow TJ, Kondo N, Amano T, Shiojiri T, Koga S (2011) The relationship between muscle deoxygenation and activation in different muscles of the quadriceps during cycle ramp exercise. J Appl Physiol 111:1259-1265. https://doi. org/10.1152/japplphysiol.01216.2010

Craig JC, Broxterman RM, Wilcox SL, Chen C, Barstow TJ (2017) Effect of adipose tissue thickness, muscle site, and sex on nearinfrared spectroscopy derived total-[hemoglobin + myoglobin]. J Appl Physiol 123:1571-1578. https://doi.org/10.1152/jappl physiol.00207.2017

Dahmane R, Djordjevič S, Šimunič B, Valenčič V (2005) Spatial fiber type distribution in normal human muscle: Histochemical and tensiomyographical evaluation. J Biomech 38:2451-2459. https://doi.org/10.1016/j.jbiomech.2004.10.020

Dawson JM, Tyler KR, Hudlicka O (1987) A comparison of the microcirculation in rat fast glycolytic and slow oxidative muscles at rest and during contractions. Microvasc Res 33:167-182. https://doi.org/10.1016/0026-2862(87)90015-x

DiMenna FJ, Bailey SJ, Jones AM (2010a) Influence of body position on muscle deoxy $[\mathrm{Hb}+\mathrm{Mb}]$ during ramp cycle exercise. Respir Physiol Neurobiol 173:138-145. https://doi.org/10.1016/j. resp.2010.07.005

DiMenna FJ, Wilkerson DP, Burnley M, Bailey SJ, Jones AM (2010b) Priming exercise speeds pulmonary $\mathrm{O}_{2}$ uptake kinetics during supine "work-to-work" high-intensity cycle exercise. J Appl Physiol 108:283-292. https://doi.org/10.1152/japplphysi ol.01047.2009

Faulkner JA, Heigenhauser GJ, Schork MA (1977) The cardiac output-oxygen uptake relationship of men during graded bicycle ergometry. Med Sci Sports 9:148-154

Ferreira LF, McDonough P, Behnke BJ, Musch TI, Poole DC (2006) Blood flow and $\mathrm{O}_{2}$ extraction as a function of $\mathrm{O}_{2}$ uptake in muscles composed of different fiber types. Respir Physiol Neurobiol 153:237-249. https://doi.org/10.1016/j.resp.2005.11.004

Ferreira LF, Hueber DM, Barstow TJ (2007a) Effects of assuming constant optical scattering on measurements of muscle oxygenation by near-infrared spectroscopy during exercise. J Appl Physiol 102:358-367. https://doi.org/10.1152/japplphysiol.00920.2005

Ferreira LF, Koga S, Barstow TJ (2007b) Dynamics of noninvasively estimated microvascular $\mathrm{O}_{2}$ extraction during ramp exercise. $\mathrm{J}$ Appl Physiol 103:1999-2004. https://doi.org/10.1152/japplphysi ol.01414.2006

Fukuoka Y, Poole DC, Barstow TJ, Kondo N, Nishiwaki M, Okushima D, Koga S (2015) Reduction of $\dot{V} \mathrm{O}_{2}$ slow component by priming exercise: novel mechanistic insights from time-resolved nearinfrared spectroscopy. Physiol Rep 3(6): e12432. https://doi. org/10.14814/phy2.12432

Gollnick PD, Piehl K, Saltin B (1974) Selective glycogen depletion pattern in human muscle fibres after exercise of varying intensity and at varying pedalling rates. J Physiol (Lond) 241:45-57

Goulding RP, Roche DM, Marwood S (2017) Prior exercise speeds pulmonary oxygen uptake kinetics and increases critical power during supine but not upright cycling. Exp Physiol 102:1158-1176. https://doi.org/10.1113/EP086304

Goulding RP, Roche DM, Marwood S (2018a) Elevated baseline work rate slows pulmonary oxygen uptake kinetics and decreases critical power during upright cycle exercise. Physiol Rep 6 (14): e13802. https://doi.org/10.14814/phy2.13802

Goulding RP, Roche DM, Marwood S (2018b) "Work-to-Work" exercise slows pulmonary oxygen uptake kinetics, decreases critical power, and increases W' during supine cycling. Physiol Rep 6 (21):e13916. https://doi.org/10.14814/phy2.13916

Goulding RP, Roche DM, Marwood S (2019a) Hyperoxia speeds pulmonary oxygen uptake kinetics and increases critical power during supine cycling. Exp Physiol 104 (7): 1061-1073. https://doi. org/10.1113/EP087599
Goulding RP, Roche DM, Marwood S (2019b) Effect of hyperoxia on critical power and $V \mathrm{O}_{2}$ kinetics during upright cycling. Med Sci Sports Exerc 52 (5):1041-1049. https://doi.org/10.1249/ MSS.0000000000002234

Goulding RP, Marwood S, Okushima D, Poole DC, Barstow TJ, Lei T-H, Kondo N, Koga S (2020a) Effect of priming exercise and body position on pulmonary oxygen uptake and muscle deoxygenation kinetics during cycle exercise. J Appl Physiol 129 (4): 810-822. https://doi.org/10.1152/japplphysiol.00478.2020

Goulding RP, Okushima D, Marwood S, Poole DC, Barstow TJ, Lei T-H, Kondo N, Koga S (2020b) Impact of supine exercise on muscle deoxygenation kinetics heterogeneity: mechanistic insights into slow pulmonary oxygen uptake dynamics. J Appl Physiol 129 (3): 535-546. https://doi.org/10.1152/japplphysiol.00213.2020

Goulding RP, Roche DM, Scott SN, Koga S, Weston PJ, Marwood S (2020c) Limitations to exercise tolerance in type 1 diabetes: the role of pulmonary oxygen uptake kinetics and priming exercise. J Appl Physiol 128 (5): 1299-1309. https://doi.org/10.1152/jappl physiol.00892.2019

Grassi B, Rossiter HB, Zoladz JA (2015) Skeletal muscle fatigue and decreased efficiency: two sides of the same coin? Exerc Sport Sci Rev 43:75-83. https://doi.org/10.1249/JES.0000000000000043

Heinonen I, Kemppainen J, Kaskinoro K, Peltonen JE, Borra R, Lindroos MM, Oikonen V, Nuutila P, Knuuti J, Hellsten Y, Boushel R, Kalliokoski KK (2010) Comparison of exogenous adenosine and voluntary exercise on human skeletal muscle perfusion and perfusion heterogeneity. J Appl Physiol 108:378-386. https://doi.org/10.1152/japplphysiol.00745.2009

Heinonen I, Koga S, Kalliokoski KK, Musch TI, Poole DC (2015) Heterogeneity of muscle blood flow and metabolism: influence of exercise, aging, and disease states. Exerc Sport Sci Rev 43:117124. https://doi.org/10.1249/JES.0000000000000044

Hogan MC, Arthur PG, Bebout DE, Hochachka PW, Wagner PD (1992) Role of $\mathrm{O}_{2}$ in regulating tissue respiration in dog muscle working in situ. J Appl Physiol 73:728-736. https://doi.org/10.1152/jappl 1992.73.2.728

Iannetta D, Inglis EC, Pogliaghi S, Murias JM, Keir DA (2020) A "step-ramp-step" protocol to identify the maximal metabolic steady state. Med Sci Sports Exerc 52:2011-2019. https://doi. org/10.1249/MSS.0000000000002343

Jackman MR, Willis WT (1996) Characteristics of mitochondria isolated from type I and type IIb skeletal muscle. Am J Physiol 270:C673-678. https://doi.org/10.1152/ajpcell.1996.270.2.C673

Jennekens FGI, Tomlinson BE, Walton JN (1971) Data on the distribution of fibre types in five human limb muscles. An autopsy study. J Neurol Sci 14:245-257. https://doi.org/10.1016/0022510X(71)90215-2

Johnson MA, Polgar J, Weightman D, Appleton D (1973) Data on the distribution of fibre types in thirty-six human muscles. An autopsy study. J Neurol Sci 18:111-129

Jones AM, Berger NJA, Wilkerson DP, Roberts CL (2006) Effects of "priming" exercise on pulmonary $\mathrm{O}_{2}$ uptake and muscle deoxygenation kinetics during heavy-intensity cycle exercise in the supine and upright positions. J Appl Physiol 101:1432-1441. https ://doi.org/10.1152/japplphysiol.00436.2006

Kalliokoski KK, Kemppainen J, Larmola K, Takala TO, Peltoniemi P, Oksanen A, Ruotsalainen U, Cobelli C, Knuuti J, Nuutila P (2000) Muscle blood flow and flow heterogeneity during exercise studied with positron emission tomography in humans. Eur J Appl Physiol 83:395-401. https://doi.org/10.1007/s004210000267

Kalliokoski KK, Laaksonen MS, Takala TO, Knuuti J, Nuutila P (2003) Muscle oxygen extraction and perfusion heterogeneity during continuous and intermittent static exercise. J Appl Physiol 94:953958. https://doi.org/10.1152/japplphysiol.00731.2002

Keir DA, Benson AP, Love LK, Robertson TC, Rossiter HB, Kowalchuk JM (2015) Influence of muscle metabolic heterogeneity 
in determining the $V \mathrm{o} 2 \mathrm{p}$ kinetic response to ramp-incremental exercise. J Appl Physiol 120:503-513. https://doi.org/10.1152/ japplphysiol.00804.2015

Kindig CA, Richardson TE, Poole DC (2002) Skeletal muscle capillary hemodynamics from rest to contractions: implications for oxygen transfer. J Appl Physiol 92:2513-2520. https://doi.org/10.1152/ japplphysiol.01222.2001

Koga S, Shiojiri T, Shibasaki M, Kondo N, Fukuba Y, Barstow TJ (1999) Kinetics of oxygen uptake during supine and upright heavy exercise. J Appl Physiol 87:253-260

Koga S, Poole DC, Ferreira LF, Whipp BJ, Kondo N, Saitoh T, Ohmae E, Barstow TJ (2007) Spatial heterogeneity of quadriceps muscle deoxygenation kinetics during cycle exercise. J Appl Physiol 103:2049-2056. https://doi.org/10.1152/japplphysiol.00627.2007

Koga S, Poole DC, Fukuoka Y, Ferreira LF, Kondo N, Ohmae E, Barstow TJ (2011) Methodological validation of the dynamic heterogeneity of muscle deoxygenation within the quadriceps during cycle exercise. Am J Physiol Regul Integr Comp Physiol 301:R534-541. https://doi.org/10.1152/ajpregu.00101.2011

Koga S, Barstow TJ, Okushima D, Rossiter HB, Kondo N, Ohmae E, Poole DC (2015) Validation of a high-power, time-resolved, near-infrared spectroscopy system for measurement of superficial and deep muscle deoxygenation during exercise. J Appl Physiol 118:1435-1442. https://doi.org/10.1152/japplphysiol.01003.2014

Koga S, Okushima D, Barstow TJ, Rossiter HB, Kondo N, Poole DC (2017) Near-infrared spectroscopy of superficial and deep rectus femoris reveals markedly different exercise response to superficial vastus lateralis. Physiol Rep 5(17): e13402. https://doi. org/10.14814/phy2.13402

Koga S, Okushima D, Poole DC, Rossiter HB, Kondo N, Barstow TJ (2019) Unaltered $\dot{V} \mathrm{O}_{2}$ kinetics despite greater muscle oxygenation during heavy-intensity two-legged knee extension versus cycle exercise in humans. Am J Physiol Regul Integr Compar Physiol 317:R203-R213. https://doi.org/10.1152/ajpregu.00015.2019

Krustrup P, Söderlund K, Mohr M, González-Alonso J, Bangsbo J (2004) Recruitment of fibre types and quadriceps muscle portions during repeated, intense knee-extensor exercise in humans. Pflugers Arch 449:56-65. https://doi.org/10.1007/s0042 4-004-1304-3

Laughlin MH, Armstrong RB (1982) Muscular blood flow distribution patterns as a function of running speed in rats. Am J Physiol 243:H296-306

Laughlin MH, Davis MJ, Secher NH, van Lieshout JJ, Arce-Esquivel AA, Simmons GH, Bender SB, Padilla J, Bache RJ, Merkus D, Duncker DJ (2012) Peripheral circulation. Compr Physiol 2:321447. https://doi.org/10.1002/cphy.c100048

Lexell J, Henriksson-Larsén K, Sjöström M (1983) Distribution of different fibre types in human skeletal muscles. 2. A study of cross-sections of whole m. vastus lateralis. Acta Physiol Scand 117:115-122. https://doi.org/10.1111/j.1748-1716.1983.tb071 85. $\mathrm{x}$

McDonough P, Behnke BJ, Padilla DJ, Musch TI, Poole DC (2005) Control of microvascular oxygen pressures in rat muscles comprised of different fibre types. J Physiol (Lond) 563:903-913. https://doi.org/10.1113/jphysiol.2004.079533

Meyer RA, Foley JM (2010) Cellular processes integrating the metabolic response to exercise. In: Comprehensive physiology. Wiley, Oxford. https://doi.org/https://doi.org/10.1002/cphy.cp120118

Moritani T, Sherman WM, Shibata M, Matsumoto T, Shinohara M (1992) Oxygen availability and motor unit activity in humans. Eur J Appl Physiol Occup Physiol 64:552-556. https://doi. org/10.1007/bf00843767

Moritani T, Takaishi T, Matsumoto T (1993) Determination of maximal power output at neuromuscular fatigue threshold. J Appl Physiol 74:1729-1734. https://doi.org/10.1152/jappl.1993.74.4.1729
Murgatroyd SR, Ferguson C, Ward SA, Whipp BJ, Rossiter HB (2011) Pulmonary $\mathrm{O}_{2}$ uptake kinetics as a determinant of high-intensity exercise tolerance in humans. J Appl Physiol 110:1598-1606. https://doi.org/10.1152/japplphysiol.01092.2010

Murias JM, Spencer MD, Keir DA, Paterson DH (2013) Systemic and vastus lateralis muscle blood flow and $\mathrm{O} 2$ extraction during ramp incremental cycle exercise. Am J Physiol Regul Integr Comp Physiol 304:R720-725. https://doi.org/10.1152/ajpregu.00016 .2013

Ohmae E, Nishio S, Oda M, Suzuki H, Suzuki T, Ohashi K, Koga S, Yamashita Y, Watanabe H (2014) Sensitivity correction for the influence of the fat layer on muscle oxygenation and estimation of fat thickness by time-resolved spectroscopy. J Biomed Opt 19:067005. https://doi.org/10.1117/1.JBO.19.6.067005

Okushima D, Poole DC, Rossiter HB, Barstow TJ, Kondo N, Ohmae E, Koga S (2015) Muscle deoxygenation in the quadriceps during ramp incremental cycling: deep vs. superficial heterogeneity. J Appl Physiol 119:1313-1319. https://doi.org/10.1152/japplphysi ol.00574.2015

Okushima D, Poole DC, Barstow TJ, Rossiter HB, Kondo N, Bowen TS, Amano T, Koga S (2016) Greater $\mathrm{VO}_{2}$ peak is correlated with greater skeletal muscle deoxygenation amplitude and hemoglobin concentration within individual muscles during ramp-incremental cycle exercise. Physiol Rep 4:e13065. https://doi.org/10.14814/ phy 2.13065

Okushima D, Poole DC, Barstow TJ, Kondo N, Chin LMK, Koga S (2020) Effect of differential muscle activation patterns on muscle deoxygenation and microvascular haemoglobin regulation. Exp Physiol 105:531-541. https://doi.org/10.1113/EP088322

Piiper J, Pendergast DR, Marconi C, Meyer M, Heisler N, Cerretelli $\mathrm{P}$ (1985) Blood flow distribution in dog gastrocnemius muscle at rest and during stimulation. J Appl Physiol 58 (6): 2068-2074. https://doi.org/10.1152/jappl.1985.58.6.2068

Poole DC, Jones AM (2012) Oxygen uptake kinetics. Compr Physiol 2:933-996. https://doi.org/10.1002/cphy.c100072

Poole DC, Ferreira LF, Behnke BJ, Barstow TJ, Jones AM (2007) The final frontier: oxygen flux into muscle at exercise onset. Exerc Sport Sci Rev 35:166-173. https://doi.org/10.1097/jes.0b013 e318156e4ac

Poole DC, Barstow TJ, McDonough P, Jones AM (2008) Control of oxygen uptake during exercise. Med Sci Sports Exerc 40:462-474. https://doi.org/10.1249/MSS.0b013e31815ef29b

Quaresima V, Farzam P, Anderson P, Farzam PY, Wiese D, Carp SA, Ferrari M, Franceschini MA (2019) Diffuse correlation spectroscopy and frequency-domain near-infrared spectroscopy for measuring microvascular blood flow in dynamically exercising human muscles. J Appl Physiol 1985(127):1328-1337. https:// doi.org/10.1152/japplphysiol.00324.2019

Rossiter HB (2010) Exercise: kinetic considerations for gas exchange. In: Comprehensive physiology. Wiley, Oxford. https://doi. org/https://doi.org/10.1002/cphy.c090010

Spencer MD, Murias JM, Paterson DH (2012) Characterizing the profile of muscle deoxygenation during ramp incremental exercise in young men. Eur J Appl Physiol 112:3349-3360. https://doi. org/10.1007/s00421-012-2323-y

Wagner PD (1996) Determinants of maximal oxygen transport and utilization. Annu Rev Physiol 58:21-50. https://doi.org/10.1146/ annurev.ph.58.030196.000321

Whipp BJ, Ward SA (1992) Pulmonary gas exchange dynamics and the tolerance to muscular exercise: effects of fitness and training. Ann Physiol Anthropol 11:207-214

Whipp BJ, Davis JA, Torres F, Wasserman K (1981) A test to determine parameters of aerobic function during exercise. J Appl Physiol Respir Environ Exerc Physiol 50:217-221. https://doi. org/10.1152/jappl.1981.50.1.217 
Willis WT, Jackman MR (1994) Mitochondrial function during heavy exercise. Med Sci Sports Exerc 26:1347-1353

Wilson DF, Erecińska M, Drown C, Silver IA (1977) Effect of oxygen tension on cellular energetics. Am J Physiol 233:C135-140. https ://doi.org/10.1152/ajpcell.1977.233.5.C135
Publisher's Note Springer Nature remains neutral with regard to jurisdictional claims in published maps and institutional affiliations. 